\title{
Medical equipment donations in Haiti: flaws in the donation process
}

\author{
Roger Dzwonczyk ${ }^{1}$ and Chris Riha ${ }^{2}$
} $\begin{array}{ll}\text { Suggested citation } & \text { Dzwonczyk R, Riha C. Medical equipment donations in Haiti: flaws in the donation process. Rev } \\ & \text { Panam Salud Publica. 2012;31(4):345-8. }\end{array}$

ABSTRACT The magnitude 7.0 earthquake that struck Haiti on 12 January 2010 devastated the capital city of Port-au-Prince and the surrounding area. The area's hospitals suffered major structural damage and material losses. Project HOPE sought to rebuild the medical equipment and clinical engineering capacity of the country. A team of clinical engineers from the United States of America and Haiti conducted an inventory and assessment of medical equipment at seven public hospitals affected by the earthquake. The team found that only $28 \%$ of the equipment was working properly and in use for patient care; another $28 \%$ was working, but lay idle for technical reasons; $30 \%$ was not working, but repairable; and $14 \%$ was beyond repair. The proportion of equipment in each condition category was similar regardless of whether the equipment was present prior to the earthquake or was donated afterwards.

This assessment points out the flaws that existed in the medical equipment donation process and reemphasizes the importance of the factors, as delineated by the World Health Organization more than a decade ago, that constitute a complete medical equipment donation.

Key words Equipment and supplies, hospital; equipment and supplies, disasters; Haiti.

The international community endeavors to bring humanitarian aid to struggling people, whether in times of natural or human-induced disaster, or simply in an ongoing effort to help a developing nation improve its well-being. Medical response comes not only through financial support, but also in the form of personnel, supplies, drugs, medical equipment, and health facility reconstruction to help treat disease and injuries and to improve the overall level of health care and the quality of peoples' lives. Medical technology is a key component

Department of Anesthesiology, The Ohio State University, Columbus, Ohio, United States of America. Send correspondence to: Roger Dzwonczyk, email: dzwonczyk.1@osu.edu

2 Clinical Systems Engineering, Carilion Clinic, Roanoke, Virginia, United States of America. of medical aid. The equipment provides caregivers with the tools needed to help do their job effectively. However, while the donor's intent is honorable, basic flaws in the donor-recipient relationship often lead to unintended, long-term, negative consequences. This report examines the status of medical equipment in Haiti and shows the persistence of the flaws that were addressed by the World Health Organization (WHO) over a decade ago (1).

\section{Context}

The 7.0 magnitude earthquake that struck Haiti on 12 January 2010 devastated the capital city of Port-au-Prince and the surrounding area, causing widespread infrastructural damage and thousands of deaths and injuries. Several of the area's hospitals, which typically serve the majority of the population, suffered extensive infrastructural damage and material losses.

In the aftermath, numerous governments, non-governmental organizations, and medical centers from around the world contributed humanitarian medical assistance and equipment to Haiti. Among them was Project HOPE (Millwood, Virginia, United States), a nonprofit healthcare organization that provides wide-ranging humanitarian and educational aid to the underserved in developing countries. Among other things, Project HOPE has a strong, active technical focus and expertise in building clinical engineering (CE, often referred to as biomedical engineering) capacity at all levels in the developing world (2). 


\section{METHODS}

Six months after the earthquake, Project HOPE funded a medical equipment inventory and assessment project as a starting point for developing a proposal to improve equipment and CE capacity in Haiti. The project was conducted at seven public hospitals, identified by the Ministry of Health (MSPP) as containing an estimated $60 \%$ of the nation's public health care equipment. A team of seven clinical engineers-three from the United States and four from Haiti-conducted the study. Included were all patient-related monitors, diagnostic and therapeutic equipment, and clinical laboratory equipment. The CE team recorded all basic pertinent equipment data, as available, including manufacturer, model number, serial number, age, and location within the hospital. The team identified, as available, the original provider of the equipment, and established whether the equipment was obtained before or after the earthquake. The team assessed the condition of each piece of equipment and assigned it to one of four possible condition categories:

- working and in use;

- working, but not in use;

- not working, but repairable; or

- not working and not repairable.

The data were analyzed descriptively in order to establish a benchmark for long-term $\mathrm{CE}$ and medical equipment capacity-building by Project HOPE.

\section{RESULTS}

Over a 2-week period in June 2010, the CE team inventoried and assessed 951 items, essentially $100 \%$ of the clinical medical equipment at seven MSPP public hospitals in the Port-au-Prince metropolitan area (Table 1).

The equipment inventoried included standard bedside patient monitors and therapeutic equipment (blood pressure monitors, pulse oximeters, defibrillators, oxygen concentrators); standard operating room (OR) equipment (OR tables, anesthesia machines, surgical lights, anesthesia monitors, electrosurgery units, suction machines); basic dental equipment; and basic diagnostic imaging equipment (x-ray machines, film developers, ultrasound, endoscopy). One hospital, Hôpital de l’Université d'Etat
TABLE 1. Medical equipment assessed at seven public hospitals in the Port-au-Prince metropolitan area, Haiti, 2010

\begin{tabular}{|c|c|c|}
\hline Hospital & Type & Equipment units \\
\hline Croix des Bouquet & Maternity & 13 \\
\hline Eleazar Germain & General & 50 \\
\hline Hôpital l'Université d'Etat d'Haiti & General; university teaching & 634 \\
\hline Isaie Jeanty & Maternity & 56 \\
\hline La Paix & General & 107 \\
\hline Sanatorium & Chronic pulmonary & 68 \\
\hline St. Catherine Laboure & General & 23 \\
\hline
\end{tabular}

d'Haiti (HUEH), the university hospital had a functioning dialysis unit that included a water purification system. The clinical laboratories included microscopes, incubator ovens, centrifuges, blood analyzers, refrigerators, and other standard analytic equipment.

The team did not find any diagnostic or therapeutic medical equipment that might be considered too sophisticated for the Haitian healthcare environment. Aside from the emergency department at $\mathrm{HUEH}$, there were essentially no monitored beds at the time in any of the hospitals assessed. Surprisingly, only $12 \%$ of the equipment had been obtained after the earthquake. The vast majority of the equipment $(86 \%)$ had been donated to the hospitals prior to the earthquake and only a small percentage of the equipment $(2 \%)$ had been purchased as new by the hospitals. Sixty-seven percent of the equipment was located at $\mathrm{HUEH}$, the largest of the seven facilities inventoried.
This university medical center had sustained significant infrastructural damage and material loss from the earthquake.

Regarding the condition of the equipment at the time of the assessment (Figure 1), only $28 \%$ was working and in use by the medical staff for patient care; another $28 \%$ was working and not in use; and $30 \%$ was not working, but repairable (in the opinion of the CE team). Equipment that was working, but was not in use, lacked either ancillary parts and/ or supplies, (e.g., probes, patient cables, extension sets) or an appropriate location (e.g., no functioning OR for the OR equipment). Only $14 \%$ of the equipment was not working and not repairable.

Regarding the two equipment source categories, i.e., obtained before or after the earthquake, there was a nearly even distribution among the first three condition categories (working/in use, working/not in use, and not working/repairable), with each category having $24 \%-32 \%$ of the
FIGURE 1. Condition of medical equipment assessed at seven public hospitals in the Port-au-Prince metropolitan area, by equipment source, Haiti, 2010

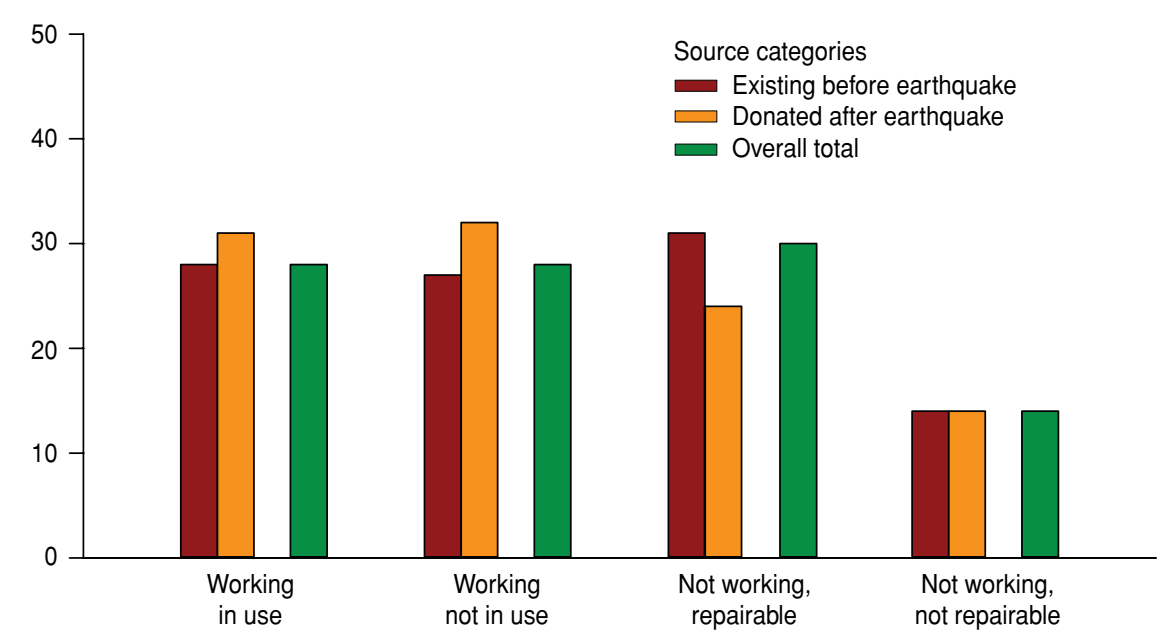

Equipment condition 
equipment. Only $14 \%$ of the equipment in each of the source categories was not working and not repairable.

The CE team was able to establish the age of only $38 \%$ of the equipment with reasonable confidence. From this sample, the team estimated that $88 \%$ of the equipment was more than 5 years old. Of the total, 304 items (32\%) either had an inventory tag from another hospital, were marked as having been owned by another hospital, or were known by the staff to have come from another hospital. This information suggested that at least this portion of the equipment had been used before its donation. Only 30\% of the equipment donated after the earthquake (35/115 items) was working and in use. Fourteen percent of the equipment (16/115 items) donated after the earthquake was not working and not repairable.

Among the entire inventory of the seven hospitals, only 10 user manuals and four service manuals were found. The Haitian CEs on the team indicated that they were responsible for servicing essentially all of the equipment at six of the seven hospitals assessed. The CE team found only two pieces of equipment (an anesthesia machine and a laboratory refrigerator) that were marked as having been serviced by a local thirdparty service provider.

Only two hospitals had CE departments. The largest department, in terms of number of personnel, was located at HUEH. The CE departments had only a few ordinary tools and testing equipment, as well as some common electrical, electronic, and mechanical spare parts. With no supply of equipment-specific spare parts, the Haitian CEs scavenged parts from inoperable equipment for repairs. It was evident that the CE departments functioned on a reactive, rather than proactive basis. Preventive maintenance was not part of the mode of operation.

Of particular note, the CEs inventoried one new (in the box) laboratory incubator oven, donated after the earthquake, that required a higher electrical voltage than the Haitian standard (240VAC versus $120 \mathrm{VAC}$ ). In addition, the team recorded eight used dialysis machines, received after the earthquake, that never worked according to the dialysis staff. These machines lacked consumables and operating manuals and were from 4-11 years old, on average older than the six dialysis machines that were in clinical service at the time of the assessment (mean 8 years old vs. 5 years old).

\section{DISCUSSION}

In 2000, WHO published guidelines that delineated a thoughtful, detailed process and four principles for making medical equipment donations (1):

(a) Health care equipment donations should benefit the recipient to the maximum extent possible;

(b) Donations should be given with due respect for the wishes and authority of the recipient, and in conformity with government policies and administrative arrangements of the recipient country;

(c) There should be no double standard in quality. If the quality of an item is unacceptable in the donor country, it is also unacceptable as a donation;

(d) There should be effective communication between the donor and the recipient, with all donations made according to a plan formulated by both parties.

The data collected in this assessment suggest that the medical equipment donations made to Haiti, both before and after the 2010 earthquake, fell short of these guidelines. Reports of donated medical equipment worldwide have indicated that $25 \%-50 \%$, and as much as $70 \%$ in sub-Saharan Africa, is unusable $(1,3-7)$. Although this is 20- to 30-yearold data, the data in this report show that a similar proportion of medical equipment donated to Haiti is currently not being used (Figure 1). Aside from the equipment that lacked an appropriate space, that which was working, but not in use, was simply missing ancillary parts/supplies and/or user manuals. Judging from existing inventory tags, more than one-third of the equipment $(38 \%)$ had been used prior to donation; from experience, it is most likely more. Furthermore, preventive maintenance and calibration should be part of the donation process for used medical equipment. It is questionable whether maintenance had been performed on the eight nonfunctioning dialysis machines at HUEH.

Often, an equipment donation is a knee-jerk reaction to an emergent disaster or a presumed need. Without proper communication, many donations will fall short of the intended goal. It is human nature to accept a donation of any kind, even without a plan for its use. If there is no advocate on the receiving end, the equipment is often put aside and eventually forgotten. Depending on the scope of the donation, the recipientadvocate could be a hospital staff member, hospital administrator, a member of the health ministry, or an intermediary helping in the country. The advocate must understand the needs of the health care system and be knowledgeable in the policies and procedures for soliciting and receiving donations. Although the WHO guidelines generally recommend against making capital donations in an emergent crisis, good communication between the donor and the recipient and a plan for long-term equipment use will improve the success of donations.

The ability to use and maintain donated equipment must be evaluated by the donor and recipient. Even older medical devices are complex instruments. The assessment process should include evaluating the recipient's technical and user capabilities to ensure proper maintenance and use. Specialized maintenance training may be necessary. Equipment repair requires service manuals, equipment-specific parts, specialized tools, and test equipment. User training is often needed to take full advantage of the medical equipment's capabilities.

A poorly conceived donation may not only be useless, but may, in fact, evoke a new unwanted financial and/or environmental burden on the recipient. Consider the incubator oven found in this assessment: the hospital will need to obtain a transformer to make use of this otherwise brand-new medical device. A study conducted in 2008 that tracked donations of oxygen concentrators to Gambia also reported this burden (2). In this case, the operating voltage, frequency, and operating temperature of the concentrators were not assessed a priori. Even though the recipient purchased transformers for the concentrators, the devices failed prematurely because they were operating outside their temperature range and at the wrong power supply frequency.

Equipment not worth fixing or modifying poses a waste disposal problem for the recipient. Many electronic devices contain contaminants such as lead, cadmium, beryllium and mercury. These substances are hazardous to handle and 
a detriment to people and the environment if they are not disposed of properly. Disposal of unwanted equipment poses another financial burden on the recipient.

\section{Recommendations}

The 2000 WHO guidelines (1) should be the cornerstone of the medical equipment donation process. The donor and recipient, as well as any intermediaries, have a responsibility to make donations complete and successful. Ideally, these responsibilities should be delineated $a$ priori in a written entity-specific policy and procedure that spells out the general technical requirements of equipment, as well as the respective logistical and regulatory requirements of the organizations, institutions, and governmental agencies involved. Some developing countries receive up to $80 \%$ of their medical equipment through donations (1). These countries, in particular, should have a clearly worded donation policy and procedure and an established office that acts as the focal point for coordinating equipment donation efforts.

Prior to making a donation, an assessment of need, usability, and sustainability is paramount. The recipient's true needs must be clearly defined so that the donor can ensure that the donation will be a benefit to the patient population. Both parties must confirm that the equipment will operate properly in the recipient's environment. The donor should ensure that the equipment is in good, safe, working condition and that it meets the manufacturers' original specifications. Used equipment should have a reasonable amount of useful life remaining; for the most part, obsolete equipment will only be a burden. Additionally, the donor and recipient must confirm that the recipient has the appropriate maintenance expertise, and that parts and materials, including techni- cal documents, are either included in the donation or are available through a supplier or service center within the recipients geographic area. It may also be helpful for the donor or an intermediary to provide technicians for the initial equipment installation, as well as for technical and user training. Lastly, a plan to follow-up and measure success should be in place to ensure that the goals of the donation have been met. Throughout the entire donation process, communication is vitally important for a complete and successful medical equipment donation.

Acknowledgements. The authors gratefully acknowledge Kenneth Edmondson, Carl Porter, Yensly Adrien D'Haiti, Yvener Beauvil, Badette Isma, and Thélémaque Wilkenson for their participation in the Project HOPE Haitian medical equipment inventory and assessment mission.

\section{REFERENCES}

1. World Health Organization. Guidelines for health equipment donations. Geneva: WHO; 2000. (WHO/ARA/97.3).

2. Project Hope. What we do. Available at: www.projecthope.org Accessed on 10 January 2012.

3. Howie SRC, Hill SE, Peel D, Sanneh M, Njie $\mathrm{M}$, Hill PC, et al. Beyond good intentions: lessons on equipment donation from an African hospital. Bull World Health Organ. 2008;86(1):52-6.
4. Wang B. A framework for health equipment management in developing countries. In: Cooper E, ed. Business briefing: Hospital engineering \& facilities management. London: World Markets Research Centre; 2003.

5. World Health Organization. Interregional meeting report: maintenance and repair of health care equipment. Geneva: WHO; 1987. (WHO/SHS/NHP/87.8).

6. Bray T. Appropriate health care technology transfer to developing countries. Proceedings
Summary, Institute for Health Policy Project. Millwood, Virginia: HOPE Center for Health Information; 1982. P. 34.

7. World Health Organization. Quality of care: patient safety. Report by the Secretariat to the Fifty-fifth World Health Assembly; Geneva: WHO; 23 March 2002. (WHO/A55/13).

Manuscript received on 10 March 2011. Revised version accepted for publication on 14 September 2011.

RESUMEN El terremoto de magnitud 7,0 que azotó a Haití el 12 de enero del 2010 devastó la capital, Puerto Príncipe, y sus alrededores. Los hospitales del área afectada sufrieron daños estructurales importantes y pérdidas materiales. El Proyecto Hope procuró reconstruir el equipo médico y la capacidad de ingeniería clínica del país. Un equipo de ingenieros clínicos de Estados Unidos y Haití realizó un inventario y una evaluación del equipo médico en siete hospitales públicos afectados por el terremoto. El equipo encontró que solo $28 \%$ del equipo estaba funcionando adecuadamente y se usaba para la atención de los pacientes; otro $28 \%$ funcionaba pero no se empleaba por razones técnicas; $30 \%$ del equipo no funcionaba, pero podía repararse; y $14 \%$ no funcionaba y no podía repararse. La proporción de equipo en cada categoría fue similar, independientemente de que el equipo estuviera presente antes del terremoto o se hubiera donado después. Esta evaluación señala las fallas en el proceso de donación de equipo médico y recalca la importancia de los factores que implica una donación completa de equipo médico, ya delineados por la Organización Mundial de la Salud hace más de un decenio.

Palabras clave Equipos y suministros de hospitales; equipos y suministros en desastres; Haití. 